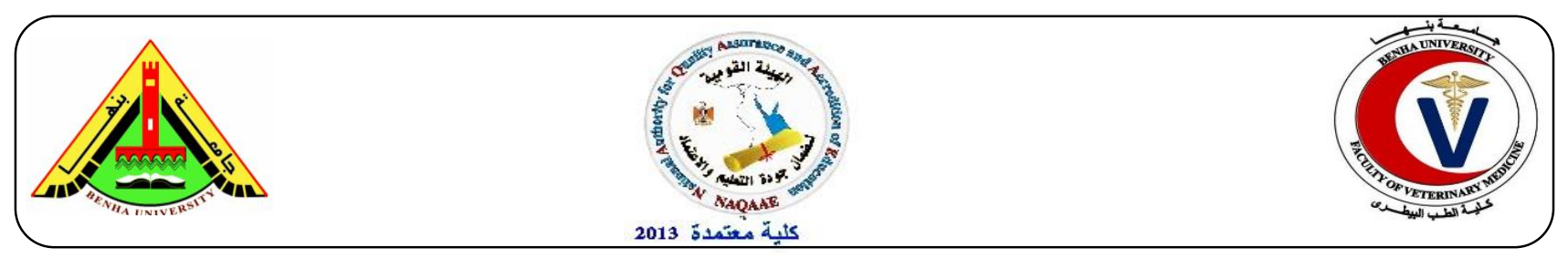

\title{
Antibacterial effect of lactic acid bacteria against psychrotrophic microorganisms in chilled minced beef meat during storage at $4^{\circ} \mathrm{c}$
}

\author{
Samar Ibrahim, Mohamed Hassan, Reham Amin, Shimaa Idris \\ Department of Food Hygiene and Control, Faculty of Veterinary Medicine, Benha University
}

\section{A B S T R A C T}

This study was conducted to investigate the antimicrobial effect of some probiotic strains (Lactobacillus casei, Lactobacillus dulbrueckii, and Bifidobacterium lactis) against psychrotrophic bacteria; which gave a promising biopreservation technique against Psychrotrophs, Pseudomonas and Aeromonas growth in chilled minced beef meat during refrigerated storage at $4{ }^{\mathrm{O}} \mathrm{C}$ for 10 days. The meat samples were divided into 4 groups (100 g. each), (A), (B) and (C) were inoculated with Lactobacillius casei, Lactobacillus delbrueckii and Bifidobacterium lactis and finally control one. Results showed a great reduction in Psychrotrophic, Pseudomonas and Aeromonas counts and reduction percent to be after $10^{\text {th }}$ day of experiment $\left(5.63 \times 10^{4} \mathrm{CFU} / \mathrm{g}(99.9 \%), 2.30 \times 10^{4} \mathrm{CFU} / \mathrm{g}\right.$

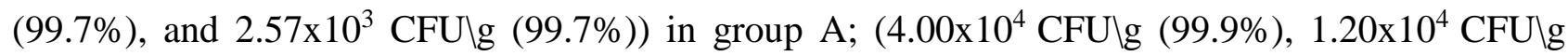

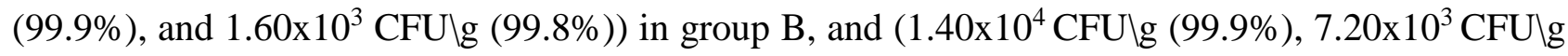

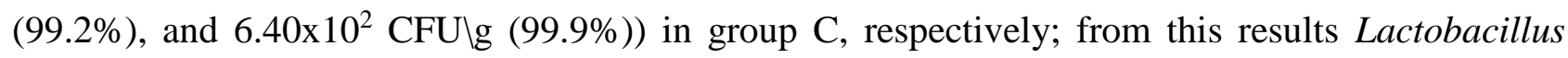
dulbrueckii showed the most antimicrobial effects within groups. Using of probiotics as biopreservatives in chilled minced beef meat are of promising trend for its health benefits and antibacterial effects especially on Psychrotrophes.

Keywords: minced meat, psychrotrophic bacteria, pseudomonas, aeromonas, probiotic.

(http://www.bvmj.bu.edu.eg)

(BVMJ-36(2): 238-246, 2019)

\section{INTRODUCTION}

Meat and meat products are very important food items in most countries as they constitute important source of high-quality protein and their amino acid composition usually compensate for shortcomings in the food. They supply easily absorbed iron and assist the absorption of iron from other foods as well as zinc; they also are rich sources of B-complex vitamins. By providing such nutrients, meat consumption can alleviate common nutritional deficiencies, which is still widespread in developing countries and secure a better child physical and mental development (Speedy, 2003).

Storage of meat for long period at low temperatures is responsible for several quality problems to meat industry. These problems related to growth of pyschrotrophic microorganism (Nasser and Fathi, 1997).

Psychrotrophic bacteria are increased in attention by many investigators in this recent years, they have the ability to grow at low temperature so they called cold-tolerant bacteria, but its maximum and optimal growth 
temperatures above 15 and $20^{\circ} \mathrm{C}$. Most of psychrotrophic microorganisms are spoilage bacteria but some of them are pathogenic (FAO, 1992).

Pshychrotrophic gram-negative bacteria, as Pseudomonas spp., make significant problem in refrigerated meat due to secretion of enzymes which has hydrolytic action especially lipase and proteases (Rajmohan et al., 2002).

In addition, recent food surveys confirmed that Aeromonas species are re-immerging enteric pathogens which responsible for several food epidemics (Ghenghesh et al., 2008).

Psychrotrophic bacteria including pseudomonas and Aeromonas may be the reason of harmful health conditions as diarrhea, meningitis, dysentery, food poisoning, infections of urinary tract and gastrointestinal infections. According to studies peoples who have risk of exposed to these harmful bacteria are pregnant, newborns, immune-compromised persons and have preexisting health. So their presence in food makes high risk as they lead to food spoilage and food poisoning (Jay, 2000).

Food preservation is a continuous effort aims to eliminate or reduce the growth of spoilage and pathogenic microorganisms in food. Until now, improving food safety has based on adding chemical preservatives, antibiotics or on application of more drastic physical treatments (refrigeration or high temperature); these methods have many drawbacks (Rassoli, 2007).

In recent years, probiotics foods have received special attention. The most commonly used probiotic microorganisms are lactobacillus and Bifidobacterium, and to a lesser degree, Enterococcus and Pediococcus due to their importance for consumer health. Probiotics have also been used as food Bioprotectors. Major efforts have been made to develop meatbased functional foods using strategies related to increasing the presence of beneficial compounds and limiting those with negative health implications (Carlos et al., 2015).

Probiotics are usually defined as microbial food supplements with beneficial effects on consumers. Most probiotics fall into the group of organisms' called lactic acid producing bacteria. One of the beneficial effect of lactic acid bacteria consumption include (I) improving intestinal tract health; (ii) enhancing the immune system, synthesizing and enhancing the bioavailability of nutrients; (iii) reducing symptoms of lactose intolerance, decreasing the prevalence of allergy in susceptible individuals; and (iv) reducing risk of certain cancers. Over time, new food products containing probiotics will emerge as well as disease-specific medical food. The establishment of standards of identity for probiotic-containing food products will serve to accelerate the developments and availability of these food products (Parvez et al., 2006). Therefore, the objective of this study was to evaluate antimicrobial efficiency of probiotics as (lactobacilli and bifidobacteria) on Psychotrophic growth in chilled minced beef. LAB exert a strong antagonistic effect against food spoilage and pathogenic microorganisms may be referred to many theories like: competitive exclusion for essential nutrients or adhesion sites of mucous cells, immune modulation, redox modification, and production of extracellular and diffusible antimicrobial metabolites such as organic acids (lactic, propionic, formic and acetic acids) which lowers $\mathrm{pH}$ of the food directly inhibits the growth of pathogenic bacteria, diacetyl, hydrogen peroxide which is a powerful oxidizing antimicrobial agent which oxidizes sulfhydryl groups and destroys bacterial enzymatic activity, carbon dioxide, antifungal compounds (fatty acids or phenyl lactic acid ) lysozymes, enzymes (proteases , amylases and lipases), and bacteriocins, which play an essential role in natural preservation, enhancing the safety and extending the shelf 
life of food products (De vuyst et al.,1994; cardirci et al., 2005; zalma et al.,2005; yesillik et al., 2010).

\section{Materials and methods}

\subsection{Experimental design:}

\section{Probiotic strains:}

Lactobacillus casei, Lactobacillus delbrueckii and Bifidobacterium lactis with adjusted concentration $\left(10^{7} \mathrm{CFU} / \mathrm{g}\right)$ were obtained ready to use from faculty of agriculture - Ain Shams University.

Minced meat sample:

$400 \mathrm{~g}$ of chilled minced beef meat sample was collected from local market in elobour city, Qalubiya governorate, Egypt; the sample was transported directly and aseptically to the laboratory in an ice box. The collected sample was divided into 4 portions (100 $\mathrm{g}$ each) following (Elkest-Maha et al., 2015);

- The first portion was left as control group (control group).

- The second portion was (group A) was inoculated with Lactobacillus casei $\left(10^{7}\right.$ $\mathrm{CFU} / \mathrm{g}$ ).

- The third portion (group B) was inoculated with Lactobacillus delbrueckii $\left(10^{7} \mathrm{CFU} / \mathrm{g}\right)$. -The third portion (Group C) was inoculated with Bifidobacterium lactis $\left(10^{7} \mathrm{CFU} / \mathrm{g}\right)$.

\subsection{Bacteriological examination:}

\subsubsection{Preparation of samples.}

preparation of meat sample for bacteriological examination was done according to (FDA, 2002): after well mixing of the four meat samples and added probiotic strains according groups separately and aerobically, samples were packaged in sterile polyethylene bags, labeled and stored at $4^{\mathrm{O}} \mathrm{C}$; accurately 25 grams of the examined sample were transferred to a sterile polyethylene bag and $225 \mathrm{ml}$ of $0.1 \%$ sterile buffered peptone water were aseptically added to the content of the bag. Each sample was then homogenized in a blender at 2000 rpm for 1-2 minutes to provide a homogenate of $1 / 10$ dilution. One $\mathrm{ml}$ from the original dilution was transferred with sterile pipette to another sterile test tube containing $9 \mathrm{ml}$ of sterile buffered peptone water and mixed well to make the next dilution, from which further decimal serial dilutions were prepared. The prepared dilutions were subjected to bacteriological examinations.

- Bacteriological counts were determined in the examined inoculated samples firstly at zero day ( 2 hours after mixing probiotic strain and meat sample), and examined every 2 days until spoilage of the meat sample (after 10 days from the zero day); samples were kept at $4^{\mathrm{O}} \mathrm{C}$ in the refrigerator until the end of the experiment.

\subsubsection{Determination of Psychrotrophic count} (ISO, 2002).

From each dilution, $1 \mathrm{ml}$ of the homogenate was transferred by using a sterile pipette into two separate sterile Petri-dishes to which approximately $15 \mathrm{ml}$ of sterile melted and tempered plate count agar $\left(45^{\circ} \mathrm{C}\right)$ were added and mixed. The inoculated plates were gently shaken in rotatory movement and left till complete solidification of the agar. The plates were inverted and incubated at $7^{\circ} \mathrm{C}$ for 10 days. The total psychrotrophic count/g was calculated on plates containing 30-300 colonies.

\subsubsection{Determination of total Pseudomonas} count (ISO, 2004).

Accurately, $0.1 \mathrm{ml}$ of each meat samples homogenate were separately inoculated into duplicate Petri-dishes of $500 \mathrm{ml}$ of Pseudomonas selective agar medium supplemented with $5 \mathrm{ml}$ glycerol and evenly spread. The inoculated plates were incubated at $25{ }^{\circ} \mathrm{C}$ for 48 hours after which all developed colonies (greenish yellow colonies) were enumerated. The average count was calculated and recorded.

\subsubsection{Determination of total Aeromonas count} (FDA, 2002):

Aeromonas agar medium is highly recommended for the selective isolation of 
Aeromonas species. Accordingly, $0.1 \mathrm{ml}$ from each of the previously prepared serial dilutions was evenly spread over the dry surface of duplicate sets of Aeromonas agar plates using a sterile bent glass spreader. The inoculated control plates were incubated at $25^{\circ} \mathrm{C}$ for 24hrs. All developed yellow colonies were enumerated; and the average Aeromonas count/g was calculated and recorded.

\subsection{Statistical analysis:}

The obtained results were statistically evaluated by application of Analysis of Variance (ANOVA) test according to Feldman et al. (2003).

\section{RESULTS}

It is evident from the results recorded in table 1 that the antibacterial effect of probiotic addition on the growth rate of Psychrotrophs was mostly effective in group $\mathrm{C}$, followed by group $\mathrm{B}$, and group $\mathrm{A}$; where psychrotrophic counts after $10^{\text {th }}$ day of incubation in treated group were $1.40 \times 10^{4}, 4.00 \times 10^{4}$, and $5.63 \times 10^{4}$ $\mathrm{CFU} / \mathrm{g}$, respectively; with reduction percent 99.9\% for all groups.
Results in Table 2 showed that the antibacterial effect of probiotic addition on the growth rate of Pseudomonas was mostly effective in group $\mathrm{C}$, followed by group B, and group A; where Pseudomonas counts after $10^{\text {th }}$ day of incubation in treated group were $7.20 \times 10^{3}$, $1.20 \times 10^{4}$, and $2.30 \times 10^{4} \mathrm{CFU} / \mathrm{g}$, with reduction percent $99.8,99.9$, and $99.7 \%$, respectively While, Results in Table 3 showed that the antibacterial effect of probiotic addition on the growth rate of Aeromonas was mostly effective in group $\mathrm{C}$, followed by group $\mathrm{B}$, and group $\mathrm{A}$; where Aeromonas counts after $10^{\text {th }}$ day of incubation in treated group were $6.40 \times 10^{2}, 1.60 \times 10^{3}, 2.57 \times 10^{3} \mathrm{CFU} / \mathrm{g}$; with reduction percent of $99.9,99.7$, and $99.8 \%$, respectively.

From the previous results, it is obvious that Bifidobacterium lactis had the most antibacterial effect against Psychrotrophs, Pseudomonas, and Aeromonas spp., followed by Lactobacillus delbrueckii, and Lactobacillus casei.

Table1: Reduction \% of psychotrophic count (cfu/g) in the examined chilled minced beef samples treated with different probiotics

\begin{tabular}{cccc}
\hline Groups & Group A & Group B & Group C \\
\hline Zero day & 36.2 & 56.9 & 73.1 \\
$2^{\text {nd }}$ day & 84.9 & 91.4 & 94.5 \\
$4^{\text {th }}$ day & 98.9 & 93.5 & 99.6 \\
$6^{\text {th }}$ day & 99.8 & 99.8 & 99.9 \\
$8^{\text {th }}$ day & 99.9 & 99.9 & 99.9 \\
$10^{\text {th }}$ day & 99.9 & 99.9 & 99.9
\end{tabular}


Samar et al. (2019). BVMJ-36(2): 238-246

Table 2: Reduction \% of Pseudomonas count (cfu/g) in the examined chilled minced beef samples treated with different probiotics

\begin{tabular}{cccc}
\hline Groups & Group A & Group B & Group C \\
\hline Zero day & 11.7 & 39.1 & 65.6 \\
$2^{\text {nd }}$ day & 65.6 & 77.7 & 88.9 \\
$4^{\text {th }}$ day & 90.3 & 92.1 & 94.6 \\
$6^{\text {th }}$ day & 98.3 & 98.7 & 99.2 \\
$8^{\text {th }}$ day & 99.3 & 99.6 & 99.2 \\
$10^{\text {th }}$ day & 99.7 & 99.9 & 99.8 \\
\hline
\end{tabular}

Table 3: Reduction \% of Aeromonas count (cfu/g) in the examined chilled minced beef samples treated with different probiotics

\begin{tabular}{cccc}
\hline Groups & Group A & Group B & Group C \\
\hline Zero day & 23.5 & 37.7 & 62.9 \\
$2^{\text {nd }}$ day & 68.3 & 83.5 & 90.2 \\
$4^{\text {th }}$ day & 87.4 & 91.3 & 94.2 \\
$6^{\text {th }}$ day & 95.7 & 69.8 & 98.2 \\
$8^{\text {th }}$ day & 98.8 & 99.2 & 99.6 \\
$10^{\text {th }}$ day & 99.7 & 99.8 & 99.9 \\
\hline
\end{tabular}

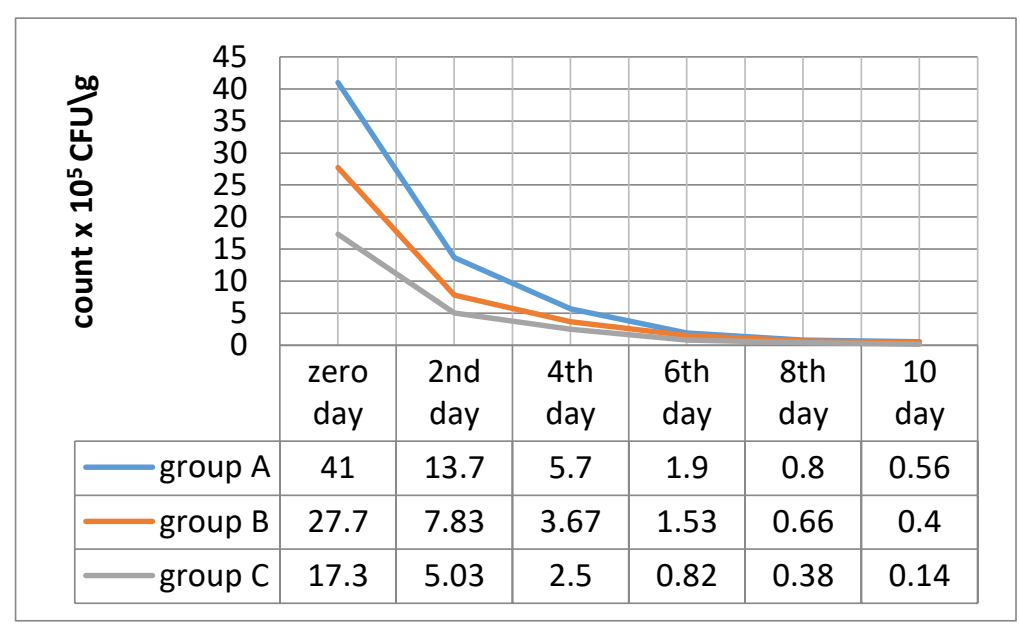

Fig.1. The effects of different probiotics on psychotrophic count (cfu/g) in the examined chilled minced beef samples 


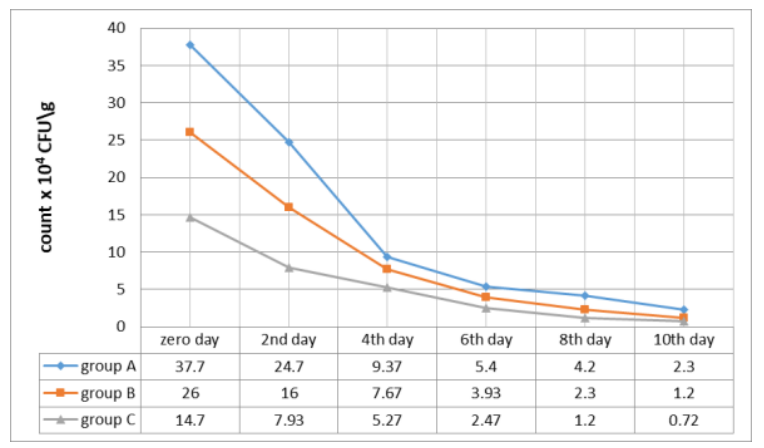

Fig.2. The effects of different probiotics on Pseudomonas count (cfu/g) in the examined chilled minced beef samples

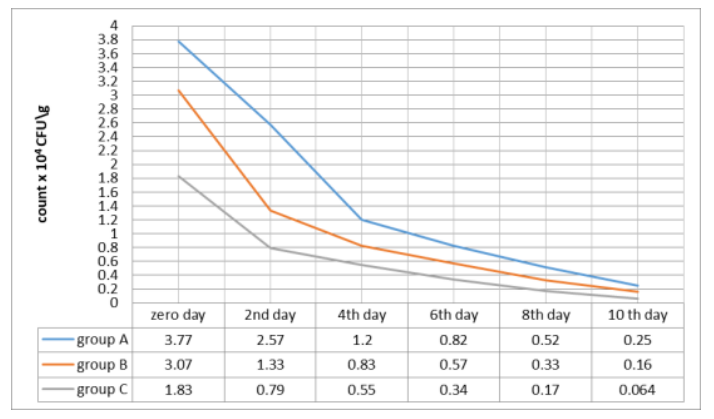

Fig.3. The effects of different probiotics on Aeromonas count (cfu/g) in the examined chilled minced beef samples

\section{DISCUSSION}

Meat products are contaminated with several types of microorganisms from different sources during preparation, processing and serving to consumers. These microorganisms varied according to the method of manufacture, quality of used non-meat ingredients and contamination level during the processing chain, packaging and storage.

Storage of meat for long period at low temperatures is responsible for several quality problems to meat industry. These problems related to growth of pyschrotrophic microorganism (Nasser and Fathi, 1997).

Food preservation is designed to enhance or protect food safety while maintaining or improving product quality by inactivating or inhibiting the growth of undesirable microorganisms (Ray, 1992).

Food preservation techniques can cause a variety of stresses that interfere with bacterial homeostasis to prevent growth or to kill bacteria. However, as a result of the stress response, some bacteria can survive and grow after the application of stress (Jones and Inouye, 1994); and due to increasing healthy food demand, FAO-WHO (2002) reported that some strains of Lactobacillus, Bifidobacterium and also some propionibacterium have been introduced as probiotics in food products due to their health-promoting effects. Bio preservation systems are of increasing interest for food industry and consumers. Bacteriocinogenic lactic acid bacteria and/or their extracted bacteriocins are considered safe additives (GRAS), useful to control the frequent development of pathogens and spoilage microorganisms in foods (SalemAmani, 2012).

Results showed in tables (1 to 3) were mostly agreed in the antibacterial effects recorded by Sidira et al. (2014) who indicated that using probiotic L. casei ATCC 393 significantly reduced the number of Pseudomonas in fermented sausages during ripening period; Mostafa et al. (2015) who studied the effect of 
three bacteriocins (from Bifidobacterium Spp.) on prevalence of some Aeromonas and Pseudomonas species in minced meat during cold storage. The effect of B. lactis Bb-12 cultures $\left(10^{6} \mathrm{CFU} / \mathrm{g}\right)$, on prevalence of some Aeromonas and Pseudomonas spp. were studied into chilled ground meat during storage for 15 days, the obtained results showed that at the end of the ninth day, the number of $P S$. fragi, Ps. flauresence, Ps. aeruginosa was reduced by $1.7 \times 10,9.6 \times 10$ and $3.1 \times 10 \mathrm{CFU} / \mathrm{g}$ for $B$. lactis $\mathrm{Bb}-12$ treatment, while the number of Aeromonas hydrophilia, A. caviae, A. sobria were reduced by $1.5 \times 10^{2}, 2.1 \times 10^{2}$ and $5.6 \times 10^{2}$ CFU/g, respectively; and Soliman et al. (2015) investigated antimoicrobial effect of three lactobacillus strains (L. acidophilus, L. casei, and $L$. plantarum) against Ps. aeruginosa in CFNS; results showed that, although $L$. acidophilus had the greatest inhibitory effect, authors recorded that all three tested lactobacilli have a good antipsedumonas effect; which may refer to the ability of Lactobacillus strains produce inhibiting substance differently act on pathogenic reference indicator strains.

While disagreed with those reported by Sharma et al. (2017) who reported weak activity of $L$. casei and $L$. delbrueckii against Pseudomonas aeruginosa.

Differences may be attributed to difference in used strain of probiotic, andlor dose of probiotic inoculum, andlor time of experiment.

\section{Conclusion}

It concluded that chilled minced beef meat were highly susceptible to psychrotrophic bacterial contamination which render food of inferior quality or even unfit for human consumption. In addition, using probiotic as bio-preservatives in chilled minced beef meat is of promising trend for its health benefits and antibacterial characteristics. The three strains of probiotic used in this experiment their effect were convergent but the fastest effect and mostly effective is Bifidobacterium lactis.

\section{REFERENCES}

Cardirci, B., Citak, A. 2005. A comparison of two methods used for measuring antagonistic activity of lactic acid bacteria. Pakistan Journal of Nutrition, 4: 237-241.

Carlos, P.C., Claudia, R.C., Ana, M.H., Francisco, J.C., Cristiano, R.M. 2015. Trends in food science and technology. International Food Research J., 21(3): 965-972.

De Vuyst, L., Vandamme, E.J. 1994. Bacteriocins of lactic acid bacteria. London, England: Blackie Academie and Professional.

Elkest-Maha, M., El-Hariri, M., Khafaga, N.I.M., Refai, M.K. 2015. Studies on contamination of dairy products by aflatoxin M1 and its control by probiotics. J. Global Biosciences, 4(1):1294-1312.

FAO-WHO. 2002. Guidelines for the evaluation of probiotics in food; Working Group Rep. Food and Health Agricultural Organization of the United Nations and World Health Organization, Washington, DC.

FDA "Food and Drug Administration" 2002. Enumeration of bacteria and identification, In: Bacteriological Analytical Manual. Center for Food Safety and Applied Nutrition, Depatment of Health and Human Searches $8^{\text {th }}$ Ed. USFDA, Chapter 4.

Feldman, D., Ganon, J., Haffman, R. and Simpson, J. 2003. The solution for data analysis and presentation graphics. $2^{\text {nd }}$ Ed., Abacus Lancripts Inc., Berkeley, USA.

Food and Agriculture Organization "FAO" 1992. Manual of Food Quality Control, Microbiological analysis. Part 4. pp. 131. 
Ghenghesh, K., Ahmed, S.F., El-Khalek, R.A., Al-Gendy, A., Klena, J. 2008. Aeromonas-associated infections in developing countries. J. Infections, 73: 1034-1037.

ISO (International Standards Organization) 2002. Horizontal method for enumeration of microorganisms, colony count technique at $30^{\circ} \mathrm{C}$. International Standards Organization, Geneva.

ISO (International Standards Organization) 2004. Microbiology of food and animal feeding stuffs. Horizontal method for detection and enumeration of Enterobacteriaceae, Part 2: colony count method. International Standards Organization, Geneva.

Jay, J.M. 2000. Fermentation and fermented dairy products. In: Modern Food Microbiology, Jay, J.M. (Ed.). $6^{\text {th }}$ Ed., Ch. 7, Springer, New York, USA, pp: 113-130.

Jones, P.G., Inouye, M. 1994. The cold-shock response- a hot topic. Molecular Microbiology J., 11: 811-818.

Mostafa, G.A., Mokhtar, M., Eldeep, G.S. 2016. Effect of bacteriocins (from Bifidobacterium spp.) on prevalence of some Aeromonas and Pseudomonas species in minced meat during cold storage. American Journal of Food Science and Nutrition, 2(4): 55-67.

Nasser, A., Fathi, S.H. 1997. Prevalence a psychrotrophic microorganism in imported frozen meat. Fleischwirtschaft, 87: 25 -27.

Parvez, S., Malik, K.A., Ah Kang, S., Kim, H.Y. 2006. Probiotics and their fermented food products are beneficial for health. J. Applied Microbiology, 100 (6): 1171-1185.

Rajmohan, S., Dodd, C.E.R., Waites, W.M. 2002. Enzymes from isolates of Pseudomonas fluorescens involved in food spoilage. J. Applied Sciences, 93(2):205-213.
Rassoli, I. 2007. Food preservation: A biopreservative approach. Food Global Science Books, pp: 111-136.

Ray, B. 1992. Nisin of Lactococcus lactis sub sp. Lactis as a food bio-preservative. pp 207-264. In: Food Biopreservatives of microbial origin. CRC Press, Boca Raton, Fla.

Salem-Amani, M. 2012. Bio-preservation challenge for shelf-life and safety improvement of minced beef. Global J. of Biotechnology \& Biochemistry, 7(2): 50-60.

Sharma, C., Singh, B.P., Thakur, N., Gulati, S. 2017. Antibacterial effects of Lactobacillus isolates of curd and human milk origin against food-borne and human pathogens. Biotechnology, 7(3): 31-39.

Shawish, R.R., Al-Humam, N.A. 2016. Contamination of beef products with Staphylococcal classical enterotoxins in Egypt and Saudi Arabia. GMS Hygiene and Infection. Control, 11: 8.

Sidira, M., Karapetsas, A., Galanis, A., Kanellaki, M., Kourkoutas, Y. 2014. Effective survival of immobilized Lactobacillus casei during ripening and heat treatment of probiotic dryfermented sausages and investigation of the microbial Dynamics. Meat Science, 96: 948-955.

Soliman, A.H.S., Sharoba A.M., Bahlol, H.E.M., Soliman, A.S., Radi, O.M.M. 2015. Evaluation of Lactobacillus acidophilus, Lactobacillus casei and Lactobacillus plantarum for probiotic characteristics. Middle East J. Agriculture Researches, 5(1): 10-18.

Speedy, A.W. 2003. Global production and consumption of animal source foods. J. Nutrition, 133(11): 4048-4053.

Yesillik, S.N., Yildirim, A.D., Yidiz, A., Yesillik, S. 2010. Antibacterial effects of some fermented commercial and homemade dairy products and $0.9 \%$ 
Samar et al. (2019). BVMJ-36(2): 238-246

lactic acid against selected foodborne pathogens. Asian Journal of Animal Veterinary Adventures, 6: 189-195.

Zalam, Z.E., Nemeth, E., Barath, A., Halasz, A. 2005. Influence of growth medium on hydrogen peroxide and bacteriocin production of lactobacillus strains. Food Technology and Biotechnology Journal, 43: 219-225. 